\title{
Dominance and Affiliation as Factors in the Social Organization of Same-sex Groups of Elementary School Children
}

\author{
Diane Carlson Jones \\ University of Michigan-Dearborn
}

\begin{abstract}
The interactional patterns among first- and secondgrade children in same-sex activity groups were analyzed in order to describe the relationships among several aspects of social organization and to examine the centrality of dominance and affiliation in social organization. Videotapes of one group of boys $(N=12)$ and one group of girls $(N=12)$ were coded. The results indicated that for both male and female groups, it was possible to specify dominance, leadership initiation, and leadership organization hierarchies. Moreover, there was a highly convergent pattern among multiple indicators of social organization centering on dominance and affiliation. However, the correlation patterns after controlling for social play suggested that the initially similar patterns were accounted for in different ways. Among the girls, the primary element linking the various dimensions was level of social play. Among the boys, there remained a smaller yet interrelated network indicating regularity in rank position for diminance, successful bids, recipient of requests, and number of play partners.
\end{abstract}

Key Words: Dominance, Affiliation, Leadership, Gender Differences, Peer Relations

\section{INTRODUCTION}

In ethological theory, the group and organizational characteristics of the group are important aspects of the social context of individual adaptation (Strayer, 1980; Omark, 1980). The structures or regularities in the dyadic relations

Received February 28, 1983; revised February 29, 1984.

Address reprint requests to: Diane Carlson Jones, Department of Behavioral Science, University of MichiganDearborn, Dearborn, MI 48128. build cohesiveness within the group as well as minimize intragroup aggression. Dominance and affiliative ties are considered the primary social mechanisms that regulate and balance the dispersive and cohesive forces within the group (Hinde, 1974; Strayer, 1980).

It is the purpose of this research to describe the relationships among affiliation, dominance, and other aspects of social organization so that we may evaluate the centrality of dominance and affiliation in the social organization of same-sex groups of elementary school children. Particular attention will be directed to differentiating power relations (dominance and leadership) in order to examine the relevance of these structures for social organization among males and females. An additional goal is to test a proposition of developmental significance made by Strayer $(1980,1981)$; that is, in groups of older children, there is greater convergence among multiple indicators of social organization. Finally, two possible explanations for the hypothesized convergence are presented and evaluated.

\section{Affiliation}

Affiliation is considered a fundamental component of social organization since affiliative ties promote the continuation of social cxchange and group cohesiveness (Hinde, 1974; McGrew, 1972; Strayer, 1980; Omark, 1980). Two aspects of affiliation have been prominently considered in the research. One approach is to identify affiliative patterns within groups by means of spatial proximity. Several studies report that group members separate themselves into identifiable 
clusters that reveal a same-sex preference (Omark, et al., 1975; Abramovitch, 1976; Lever, 1978). The other approach is to examine the individual's position within the group's affiliative network. The number of affiliative links between each child and other group members is a behavioral indicator of affiliative contacts within the group. Using this measure, it is possible to rank group members according to the extensiveness of affiliative contacts within the group and thus determine the member's degree of centrality and integration in the affiliation structure (Strayer, 1980).

\section{Dominance}

Dominance is the other central characteristic of the social ecology of many primate groups. Dominance describes asymmetric relational regularities between group members and is typically based on observed dyadic interactions that are agonistic or coercive, i.e., those that involve physical aggression, the threat of its use, or object/position displacements. Among humans, dominance hierarchies have been documented for preschoolers and adolescents. At both ages, the stabilizing of a group dominance hierarchy has been associated with a reduction in intragroup aggression (LaFreniere and Charlesworth, 1983; Savin-Williams, 1976). The importance of dominance rank as a constraint/ opportunity for individual social adaptation has also been revealed in the preferential access to resources for high ranking group members (Savin-Williams, 1976).

While it has been possible to describe dominance relations in groups of children, there have been mixed results in documenting the relevance of dominance relations for females. The outcome of studying several same-sex groups of adolescents in a camp setting has been the verification of dominance structures for females (Savin-Williams, 1979, 1980). However, in one study of mixed-sex preschoolers, females were eliminated from consideration when constructing a dominance hierarchy because they were involved in too few agonistic exchanges (McGrew, 1972). Other investigations of mixed-sex nursery school children include females in the hierarchies. In most instances, females are overrepresented in the lower portions of the dominance hierarchies, even though in some cases, the alpha child has been a girl (Strayer, 1980 . 1981).

A possible reason for the array of findings is the unwillingness of girls to compete with boys in competitive situations (Cronin, 1980; Weisfeld, et al., 1982). In a mixed-sex setting, agonistic exchanges would be either less likely to occur among males and females and/or would more likely lead to withdrawal and submission by females. This has been interpreted as adaptive because it limits unproductive competition among potential mating partners (Weisfeld, et al., 1982). However, this leaves unattended the issue of intragender competition among human females that may be obscured in mixed-sex hierarchical summaries.

\section{Leadership}

In exploring competition among females, it is important to consider whether the measurement of power relations is similar among males and females. Hrdy (1981) states that dominance is subtle among nonhuman female primates and rarely involves direct aggression. Lower rates of aggression among human females are also well documented (Maccoby and Jacklin, 1974). These findings suggest that other indicators of asymmetric power relations such as leadership should be considered.

Leadership or social control of activities has been used to indicate asymmetric relational regularities. Studies of children's groups have analyzed two different dimensions of leadership behavior during play: (1) the initiation of play activity, and (2) the organization of play activity, e.g., who was most successful in assigning roles and turn, in instructing, and generating rules of play (Hold, 1976). In most studies, only one dimension of leadership has been analyzed. For example, within same-sex adolescent groups, observed dominance status and leadership initiation were correlated (Savin-Williams, 1979). Among preschoolers, dominance has been correlated with control of play activities (Strayer, 1981). However, the relationships between the two leadership components (initiation and organization) and dominance have not been reported.

The distinction that is made between dominance and leadership is particularly relevant to the issue of gender differences in social organization. Given the lower rates of aggression and 
cultural constraints against its use, it is possible that the power dimension represented by leadership behaviors will play a more distinguishable and prominent role in the social organization of female groups.

\section{Relations among Social Organization Variables}

It has been increasingly recognized that multiple indicators of social behavior are essential in order to adequately describe social organization. Recent investigations of multiple components of social organization among preschoolers indicated that dominance and affiliation are distinct components (LaFreniere and Charlesworth, 1983; Strayer, 1980, 1981; Vaughn and Waters, 1981). However, the pattern of relations among the various social organization measures did vary with the age of the children. In the oldest group of preschoolers studied by Strayer (1980, 1981), the analyses of affiliation, dominance, social attention, and leadership revealed a convergent pattern of significant correlations. Specifically, among the five-year-olds, the dominant children were the activity leaders and occupied more central affiliative positions. Children who held higher dominance and affiliative rankings were also the initiators and recipients of the observed social activity. A more fragmented pattern of correlations was evident among the younger, four-year-old preschoolers. While these findings confound group and age differences, Strayer (1980) speculates that this preliminary finding is suggestive of important developmental changes in social organization leading to greater convergence of social roles.

If increasing convergence among indicators of social organization is a developmental phenomenon, then a pattern of interrelated organizational indicators should be evident in groups of older children. However, to date, there is no information available to evaluate this proposition.

\section{The Role of Social Activity in Social Organization}

The final area of concern in this study is to examine two possible explanations for the expected convergent pattern among organizational dimensions. The first possibility is that the pattern of intercorrelations is due to individual differences in the rate of social participation via social play with peers. Higher rates of interaction lead to increased opportunities for conflict, for influencing play activities, and for extending affiliative contacts within the group. Those individuals who exhibit greater rates of social play may be in the top positions of the hierarchy due, in part, to greater opportunities. The convergence among indices could be due to the socially active individuals attaining high rank across indices. If the convergence is due to differences in the rate of peer interaction, then controlling for the rate of interaction would diminish the intercorrelations among social structure indices.

An alternative explanation for the pattern of convergence emphasizes the regularity of successful social interactions. From this perspective, peer interaction is a necessary, but not a sufficient, condition for determining rank and convergence among the indices. Rank reflects success in negotiating conflict, in directing play activities, in soliciting attention, and in making contact with group members. The convergence among indices would be due to repeated successful negotiations and control of social interactions across indices. If the convergent pattern of correlations is function of a regularity of rank based on successful control of social interactions beyond that contributed by level of interaction, then the correlations among the social structure indices would remain intact after controlling for peer interaction.

\section{The Present Study}

Information on social organization will be derived from play behavior in same-sex groups. Observing same-sex groups will provide the opportunity to specify more clearly the patterns of social organization among females and males. First- and second-graders were selected for study in order to examine the pattern of convergence among organizational indicators in children's groups beyond the preschool years. The multiple indicators of social behavior and organization that were selected for study include dominance hierarchy, leadership initiation hierarchy, leadership organization hierarchy, and affiliative rank based on the number of play partners (Strayer, 1980). An analysis of social attention focuses on the successful initiation and receipt of bids for attention (Strayer, 1980). Requests directed to group members are also included since studies on power and dominance in 
human groups indicate that top-ranking individuals, as the controllers of resources, are the likely recipients of requests (Cartwright, 1965; Savin-Williams, 1979). An additional consideration is the identification of the individual who is more successful in making these requests.

Four issues are addressed in this study: (1) are dominance, leadership initiation, and leadership organization hierarchies identifiable in same-sex groups? (2) is a pattern of convergence among organizational measures evident in both male and female groups? (3) does the pattern center on dominance and affiliation? (4) is the pattern of convergence accounted for by level of social play or regularity in rank position?

\section{METHOD}

\section{Subjects and Setting}

One group of boys $(N=12 ; M=7-0$ years $)$ and one group of girls ( $N=12 ; M=7-3$ years) were randomly selected from a pool of volunteers for an after school activity program held one hour a week for ten weeks. The children were all middle-class whites. Six first-graders and six second-graders were randomly assigned to a same-sex activity group. Prior to the first session, the children indicated in individual interviews that they could recognize by name the photographs of approximately four other group members (boys, $M=4.3, S D=2.1$; girls, $M=$ $4.5, S D=1.5$ ).

The sessions were videotaped in the media center of the school. The room was divided into four play areas each with a separate audio channel. Play materials were dispersed throughout the play areas and were similar for male and female groups for any one week. Two adults were present at each session, but they did not initiate any interaction and rarely intervened.

Videotapes from six one-hour sessions of the boys and five sessions of the girls were analyzed for this study. To ensure representative sampling, Sessions $2,4,6,8$, and 10 were selected. In addition, Session 3 of the boys' group was included in the study. The average number of absences from the sessions was greater among the boys $(M=0.92, S D=0.17)$ than among the girls $(M=0.55, S D=1.10)$.

\section{Observational Codes}

For each event, the initiator, target, initiating, and respondent behaviors were noted. An ini- tiation was considered a behavior directed toward a person in the group. A response was defined as the behavior of the target child directed to the initiator following the initiation. The dominance, leadership, bids for attention, and request codes were event-sampled and treated as mutually exclusive categories.

\section{Dominance}

A. Initiation Behaviors

1. Physical Assertion: chase, push-pull, hit, kick, bite, wrestle, shove.

2. Threat Gesture: postural gestures of intention to hit, kick, or bite; protruding chin and forward lean.

3. Verbal Threat: comment indicating negative action intended by one child toward another, e.g., "Don't push or I'll send you to the moon."

4. Verbal Insult: insulting, derogatory, disupproving, comments, e.g., name-calling, teasing, verbal put-downs.

B. Response Behaviors

5. Submission: help-seeking, flight, crying, handcover, withdrawal.

6. Resistance: counter-attack, counterthreat.

\section{Leadership}

A. Initiation Behaviors

1. Leadership Initiation: starts an activity; verbally proposes a game.

2. Leadership Organization: directs play (e.g., assigns roles, turns); instructs (e.g., explains how or how not to carry out a particular activity); articulates, interprets, or enforces rules of play; distributes/offers objects; grants/denies play.

B. Response Behaviors

3. Compliance: follows the directives of another or replicates the activity or behavior of another.

4. Countersuggestion/Rejection: refuses to comply or presents an alternate proposal about how things should be done.

\section{Bids for Attention and Requests}

A. Initiation Behaviors

1. Bids for Attention: seeks to gain the attention/recognition of others, e.g., " Look at! Look at Craig!' 
2. Requests: asks another for an evaluation of work or self (praise); asks another how to do something (instruction); asks another for access to play, asks another for an object.

B. Response Behaviors

3. Positive Response: the child gets a visual and/or verbal response from the other (Bid for Attention): or gets positive praise, instruction, inclusion in play, or access to the object.

4. Negative Response: the child did not get visual and/or verbal response to bid for attention; or a negative response, or no response to a request.

\section{Afmiliation: Social Play}

Play in a group that is organized for the purpose of making some material product of striving to attain some competitive goal, of dramatizing situations in life, of playing formal games; or play where there is an interest in being with and associating with other (Parten, 1932).

\section{Observational Procedure}

For each of the sessions, separate tapes for each of the four play areas were viewed. Within each play area, all events of dominance, leadership, bids for attention, and requests were sampled (Altmann, 1974). Since each child had to be in one of the four play areas throughout the sessions, this method guaranteed that all incidents for each individual and the dyad were scored. Once an incident was identified, verbal and nonverbal behaviors were transcribed from the videotapes and coded. If more than one dyad were interacting in the same play area, a particular dyad was selected arbitrarily as the focial dyad for the initial pass. The procedure was repeated until all occurrences for all dyads were identified.

Scan sampling was used to assess social play. This strategy involved recording the activity of all members of a group at one minute intervals. At the end of each interval, it was noted whether each individual was engaged in social play and with whom the individual was playing. For any one session, it was possible to determine the number of intervals a child spent in social play out of all the intervals observed and the number of play partners.
The interrater reliability between two observers was based on random selection of one hour of videotapes from both male and female groups. The reliabilities calculated as total agreements/total agreements + total disagreements ranged for individual categories between $0.80-0.94$; overall agreement was 0.90 .

\section{Rate Measures}

Although the average proportion of intervals observed was similar in the two groups (boys, $M$ $=0.82, S D=0.20$; girls, $M=0.86, S D=0.17$ ), the amount of time observed for group members differed due to variation in the number of sessions observed for boys and girls, and to individual differences in the amount of time spent off camera (e.g., bathroom trips and absences). Therefore, the rates of received bids for attention and of received requests were calculated for each individual by dividing the total number of received behaviors by the number of minute intervals observed. For social play, each individual received a score based on the total number of intervals of social play/total number of intervals observed.

\section{Hierarchy Measures}

Matrix-based hierarchies were developed for dominance, leadership initiation, and leadership organization dimensions in accordance with the principles used by ethologists. For each interaction, a winner was identified as the individual who controlled the exchange process (SavinWilliams, 1979; Vaughn and Waters, 1981). The relationship was considered asymmetric if one dyad member had a greater number of wins.

A hierarchy was determined by ordering the individuals in a matrix in such a manner as to minimize the dyadic reversals (linearity) and episodic reversals (rigidity) that lie below the diagonal. Linearity indicates the degree of adherence to a transitive order while rigidity characterizes the extent to which superior ranking members control interaction sequences. Linearity and rigidity were calculated by a formula presented by Strayer and Strayer (1976). The resultant rank orders indicate that children listed higher in the sequence controlled the social interaction.

\section{Bids for Attention and Requests: Success Scores}

Success scores were calculated to specify the group members who were most successful in 
Table 1. Means and Standard Deviations for Dyadic Social Exchange Measures

\begin{tabular}{|c|c|c|c|c|}
\hline & \multicolumn{2}{|c|}{ Male } & \multicolumn{2}{|c|}{ Female } \\
\hline & Mean & S.D. & Mean & S.D. \\
\hline \multicolumn{5}{|l|}{ Mean Rates Per Hour } \\
\hline Dominance & 3.6 & 4.6 & 2.2 & 2.1 \\
\hline Leadership initiation & 2.3 & 1.4 & 2.9 & 2.5 \\
\hline Leadership organization & 11.6 & 5.7 & 15.7 & 8.8 \\
\hline Recipient requests & 4.8 & 2.4 & 6.0 & 3.0 \\
\hline $\begin{array}{l}\text { Recipient hids for } \\
\text { attention }\end{array}$ & 9.6 & 4.2 & 4.8 & 2.4 \\
\hline \multicolumn{5}{|l|}{ Mean Proportions } \\
\hline Successful requests & 0.3 & 0.2 & 0.3 & 0.2 \\
\hline $\begin{array}{l}\text { Successful bids for } \\
\text { attention }\end{array}$ & 0.5 & 0.2 & 0.4 & 0.2 \\
\hline
\end{tabular}

$a p<0.01$

$N=12$ per group

making requests and bids of attention among all group members. An individual's score was the sum of success rates (successful attempts/total attempts) with all other group members (BarnerBarry, 1977).

\section{Number of Play Partners}

The number of different play partners indicates the extensiveness of one's social contact in the group (Strayer, 1980). From the scan sampling data, each individual received a score based on the sum of the number of different group members with whom a child engaged in social play in excess of $5 \%$ of all intervals observed. This eliminated from the count the children who did not play together for at least 12 intervals across sessions.

\section{RESULTS}

\section{Rates of Dyadic Exchange}

Overall, 3,494 dyadic social exchanges were observed in the 11 hours of play group activity. An inspection of Table 1 indicates that leadership organization exchanges were the most frequent, followed by bids for attention and requests. The only significant gender difference was for bids for attention with the boys receiving nearly twice as many bids for attention as the girls. The rate of dominance exchanges was greater among the boys, although not at a significant level. While the dominance rates are not as high as those reported among preschoolers (Strayer and
Strayer, 1976; LaFreniere and Charlesworth, 1983), this difference could be due to age differences in the groups studied.

\section{Structural Hierarchies}

For each of the matrices constructed, linearity and rigidity coefficients are listed respectively: Dominance, boys, 0.93/0.80; girls, 0.97/0.77; Leadership Initiation, boys, 0.91/0.81; girls, 0.95/0.79; Leadership Organization, boys, 0.93 / $0.70 ;$ girls, $0.90 / 0.72$. These coefficients compare favorably with those reported in previous studies. Among preschoolers, the dominance hierarchy indices have ranged from $0.69-1.00$ and the leadership hierarchy indicators from 0.690.89 (LaFreniere and Charlesworth, 1983; Vaughn and Waters, 1981; Strayer, 1981; Barner-Barry, 1977).

\section{Relationships Among Social Organization Variables}

Associations among ordinal level measures were determined by Spearman rank correlations. Associations among interval level measures were tested with the Pearson statistic. The results are presented in Table 2.

Dominance rank is most frequently related to other variables for both boys and girls. Those who are more dominant in the group are also more successful in controlling play organization, making requests, and making bids. They are also more active in social play, have more play partners, and are more frequently the recipients of requests.

Such an interrelated pattern of correlations is not evident for the leadership categories. In neither group is there a significant correlation between leadership organization and leadership initiation. Apparently, those who are most successful at organizing play are different from those who control initiation activities. However, for the girls, the superior play organizers are more successful in their attempt to get the others to respond to their bids for attention and are more often the recipients of requests. The boys who are top-ranked in the leadership organization hierarchy tend to play more and have more playmates. Leadership initiation is unrelated to any of the variables for the boys. However, among the girls, it is positively related to successful requests and bids, recipient of requests, and social play. 
Table 2. Correlations Among Social Organization Measures

\begin{tabular}{|c|c|c|c|c|c|c|c|c|c|c|c|c|c|c|c|c|c|c|}
\hline & \multicolumn{2}{|c|}{ Dominance } & \multicolumn{2}{|c|}{$\begin{array}{l}\text { Leader. } \\
\text { Organ. }\end{array}$} & \multicolumn{2}{|c|}{ Leader. Init. } & \multicolumn{2}{|c|}{$\begin{array}{l}\text { Success } \\
\text { Requests }\end{array}$} & \multicolumn{2}{|c|}{ Success Bids } & \multicolumn{2}{|c|}{$\begin{array}{l}\text { Recipient } \\
\text { Requests }\end{array}$} & \multicolumn{2}{|c|}{$\begin{array}{l}\text { Recipient } \\
\text { Bids }\end{array}$} & \multicolumn{2}{|c|}{$\begin{array}{l}\text { No. Play } \\
\text { Partners }\end{array}$} & \multicolumn{2}{|c|}{ Social Play } \\
\hline & $\mathbf{M}$ & $\mathbf{F}$ & $\mathbf{M}$ & $\mathbf{F}$ & $\mathbf{M}$ & $\mathbf{F}$ & $\mathbf{M}$ & $\mathrm{F}$ & $\mathbf{M}$ & $\mathrm{F}$ & $\mathbf{M}$ & $\mathbf{F}$ & $\mathbf{M}$ & $\mathbf{F}$ & $\mathbf{M}$ & $\mathbf{F}$ & $\mathbf{M}$ & $\mathbf{F}$ \\
\hline Dominance & - & - & $0.52^{a}$ & $0.55^{a}$ & 0.17 & 0.45 & $0.78^{b}$ & $0.67^{b}$ & $0.83^{b}$ & $0.59^{a}$ & $0.68^{b}$ & $0.70^{b}$ & 0.07 & $0.57^{b}$ & $0.74^{b}$ & $0.57^{b}$ & $0.73^{b}$ & $0.73^{b}$ \\
\hline Leadership organization & 0.13 & 0.39 & - & - & 0.13 & 0.21 & 0.22 & 0.25 & 0.35 & $0.57^{a}$ & 0.40 & $0.50^{a}$ & 0.25 & 0.21 & $0.58^{a}$ & 0.17 & $0.59^{a}$ & 0.46 \\
\hline Leadership initiation & 0.28 & 0.09 & 0.26 & 0.06 & - & - & 0.42 & $0.68^{b}$ & 0.22 & $0.68^{b}$ & 0.11 & $0.53^{a}$ & 0.14 & 0.32 & 0.43 & 0.35 & 0.47 & $0.58^{a}$ \\
\hline Successful requests & 0.32 & 0.46 & $-0.60^{a}$ & 0.15 & 0.05 & 0.47 & $\ldots$ & - & $0.52^{a}$ & 0.41 & $0.50^{a}$ & $0.67^{b}$ & 0.38 & 0.44 & $0.52^{a}$ & 0.47 & $0.78^{b}$ & $0.64^{b}$ \\
\hline Successful bids & $0.78^{b}$ & 0.03 & 0.03 & $0.62^{a}$ & 0.14 & 0.39 & 0.33 & -0.20 & - & - & $0.58^{a}$ & $0.74^{b}$ & 0.19 & $0.50^{\circ}$ & $0.71^{b}$ & $0.62^{a}$ & 0.43 & $0.79^{b}$ \\
\hline Recipient requests & $0.62^{a}$ & 0.36 & 0.20 & 0.47 & 0.12 & 0.24 & 0.26 & 0.37 & 0.48 & 0.36 & - & - & 0.27 & 0.38 & $0.72^{b}$ & $0.52^{a}$ & 0.46 & $0.75^{b}$ \\
\hline Recipient bids & 0.32 & 0.28 & 0.06 & 0.33 & 0.09 & 0.29 & 0.08 & -0.21 & 0.01 & -0.46 & 0.09 & $-0.62^{a}$ & - & - & 0.29 & $0.83^{b}$ & 0.43 & $0.83^{b}$ \\
\hline No. play partners & $0.50^{a}$ & -0.15 & 0.36 & 0.08 & -0.14 & 0.24 & 0.04 & -0.23 & $0.63^{a}$ & 0.21 & $0.63^{a}$ & 0.41 & -0.01 & 0.41 & - & - & $0.68^{b}$ & $0.87^{b}$ \\
\hline \multicolumn{19}{|l|}{${ }^{a} p<0.05$} \\
\hline \multicolumn{19}{|l|}{${ }^{b} p<0.01$} \\
\hline$=12$ per group & & & & & & & & & & & & & & & & & & \\
\hline
\end{tabular}

Numbers below the diagonal are the partial Pearsonian correlations controlling for social play

Successful requests, successful bids, and recipient of requests appear as an intercorrelated cluster in both groups (the correlation between successful requests and successful bids is marginal for the girls' group). These variables are marginally or significantly related to the dominance, social play, and affiliative rank in both groups and to leadership rank in the girls' group. Recipient of bids is distinct since it is unrelated to any other variables for the boys and shows only scattered significance for the girls.

The affiliative measures are highly related to the other variables. This is especially true of social play, where marginal or positive significance is consistently noted. Additionally, the individuals with the most affiliative contacts are also the ones who are in the top positions of the dominance hierarchies, most successful in making bids and requests, and most likely to be recipients of these behaviors.

Partial correlations were calculated controlling for social play. Since there is not a measure of significance for partial correlations on ordinal data, the Pearson statistic was the appropriate choice. The results are presented in Table 2.

Overall, the pattern of interrelationships is greatly reduced once social play is controlled. Among the girls, only two isolated instances of significance persist, and two significant correlations would be expected by chance. It appears that the intercorrelations among indices initially reported were heavily influenced by the level of social activity. However, for the boys, the positive correlations between dominance rank, successful bids, recipient of requests, and number of play partners remain. These variables form an interrelated cluster that represents a regularity in social position independent of social play.

\section{DISCUSSION}

The results of this study indicate that it is possible to specify dominance, leadership initiation, and leadership organization structures within male and female groups. Of particular importance is the fact that it is possible to represent the regularities with which females resolve interpersonal power issues. Moreover, linearity and rigidity figures are quite comparable for the hierarchies of the two groups, suggesting that the characteristics of the structures are similar in these same-sex groups. The data do not support the idea proposed earlier of a greater prominence of leadership hierarchies within the female groups. It is dominance rather than leadership that is more predictive of status differences in both groups. This is revealed by the greater number of significant correlations with other measures.

The proposed convergence among the organizational components was also supported by the data for both male and female groups. The patterns of convergence were similar in both groups such that most measures were related to dominance and the affiliative measures of number of play partners and social play rates. These findings provide support for considering dominance and affiliation as central components of social organization. These results also lend support to the accumulating cross-sectional information that suggests greater convergence in the relationships among organizational indicators in older age groups (Strayer, 1980, 1981; SavinWilliams, 1979). Like the older preschoolers described by Strayer (1980, 1981), the six- and seven-year-olds who held the top dominance po- 
sitions and had the greater number of play partners were also the controllers of leadership organization, the successful initiators of requests for bids of attention, and the recipients of requests.

The major gender difference emerged when considering the basis for the pattern of convergence among organizational indicators. The correlation patterns after controlling for social play suggest that the initially similar convergent patterns may be accounted for in different ways. Among the girls, the primary element linking the various dimensions was level of social play. Apparently, those individuals who played at greater rates also tended to occupy top positions within dominance and leadership organization hierarchies and to be the recipients and initiators of successful bids for requests, since this regularity in rank or success was virtually eliminated once the contribution of social play was removed. It appears that rate of social play was an important element in accounting for hierarchical rank convergence among the organizational measures in the female group.

Among the boys, it is also true that controlling for social play decreased the degree of convergence. However, unlike the girls' group, there remained an interrelated network indicating regularity in rank position for dominance, successful bids, recipient of requests, and number of play partners. This means that regardless of level of social activity, certain members of the group controlled dominance interactions, had more extensive affiliative contacts, were more successful when making a bid for attention and were most frequently receiving requests from group members.

The group differences after partialling are important. It appears that for the girls, power and success flow to those who are socially active. Once social play is controlled, there is no longer any identifiable regularity in asymmetric relations. However, the regularities that do persist for the boys are indications that a different mechanism may operate: certain group members systematically control dyadic interaction and are central affiliative figures, independent of level of social play. Power and success are not simply a product of level of social interaction. These findings are compatible with existing ethological and psychological research that identifies dominance and extensiveness of affiliative contacts as two variables that are particularly relevant to the so- cial experience and skill of boys (Savin-Williams, 1976; Waldrop and Halverson, 1975).

The cluster of variables also provides an interesting perspective relative to the channeling of attention within the group by identifying specific behaviors that promote the differential distribution of visual and social attention. Subordinates can be considered initiators of the flow of attention when they turn to high-ranking members to make requests. High-ranking members are also actively soliciting visual attention and are more successful in getting others to look at them. While subordinate members may be looking at top-ranking members because they can learn interesting things (Vaughn and Waters, 1981), it should not be overlooked that subordinates are also responding to explicit appeals for visual regard. In these ways, both dominant and subordinate members initiate and participate in the flow of attention toward the dominant, affiliative members.

\section{CONCLUSIONS}

These results provide a much needed picture of social organization within same-sex groups of elementary school children. On the face of it, the social organization built by females is remarkably similar to that described for boys. Girls do engage in agonistic encounters that have a documented regularity of outcome best summarized by the dominance hierarchy. While leadership organization is related to dominance, it is dominance that is the most central component of power relations in both groups. The findings do suggest that competition and asymmetric relations are as much a part of female groups as male ones. These results may be limited, however, to groups of unrelated females. In this situation, intragender competition may be greater than among units of related females. Further research is necessary to determine if these findings are applicable to settings in which there are units of related females.

A central aspect of this study has been to describe the relationship between affiliation and dominance. The results point to the centrality of dominance and affiliation, and document the importance of considering both factors when describing social organization. In essence, these data suggest that we should not think of dominance as the causal factor in social organization in either group. Moreover, rather than conceiv- 
ing of dominance and affiliation as independent forces that are balanced within the group, the present study points to an alternative conceptualization emphasizing the interdependence of dominance and affiliation. Indeed, the affiliative behaviors such as social play are the context in which dispersive or agonistic relations emerge. This is indicated by the decrease in the pattern of correlations after controlling for the social play and is particularly true of the females. For the boys, dominance is not merely a product of affiliation since it is part of the cluster that remains after partialling. Still, the cluster of significant relations includes the number of play partners, a measure of affiliation within the group. While dominance may be more prominent among the boys, it is also apparent that affiliative contacts are an important part of the expression of asymmetric relations.

The results reported here must be regarded as tentative until replicated in other studies. The findings may reflect the unique styles of these children and the specific setting in which they played. Still, this investigation does identify, from a multidimensional viewpoint, several commonalities in the social organization of same-sex groups. Equally important is the reported differences in the basis for the patterns of convergence, which suggests different mechanisms for social organization among girls and boys in a group setting.

\section{REFERENCES}

Abramovitch, $R$. The relation of attention and proximity to rank in preschool children. In The Social Structure of Attention, M.R.A. Chance and R. Larsen (Eds.). London: John Wiley, 1976, pp. 153-176.

Altmann, J. Observational study of behavior. Behav. ior 49: 227-265 (1974).

Barner-Barry, C. An observational study of authority in a preschool peer group. Political Methodology 4: 415-499 (1977).

Cartwright, D. Influence, leadership, control. In Handbook of Organizations, I. March (ed.). Chicago, Rand McNally, 1965, pp. 1-47.

Caspari, E. The biological basis of female hierarchies. In Female Hierarchies, L. Tiger and H. Fowler (Eds.). Chicago: Beresford Book Service, 1978, pp. 87-102.

Cronin, C. Dominance relations and females. In Dominance Relations, D. Omark, F. Strayer, D. Freedman (Eds.). New York: Garland Press, 1980, pp. 299-318.
Hinde, R. Biological Basis of Human Social Behavior. New York: McGraw Hill, 1974.

Hold, B. Attention structure and rank specific behaviors in preschool children. In The Social Structure of Attention, M.R.A. Chance and R. Larsen (Eds.). London: John Wiley 1976, pp. 177-201.

Hrdy, S. The Woman That Never Evolved. Cambridge, Mass.: Harvard University Press, 1981.

LaFreniere, P., Charlesworth, W. Dominance, attention, and affiliation in a preschool group: A ninemonth longitudinal study. Ethology and Sociobiology 4: 53-67 (1983).

Lever, J. Sex differences in the complexity of children's play and games. American Sociological Review 43: 471-483 (1978).

Maccoby, E., Jacklin, C. The Psychology of Sex Differences. Standord, California: Stanford University Press, 1974.

McGrew, W. An Ethological Study of Children's Behavior. New York: Academic Press, 1972.

Omark, D. The group: A factor or an epiphenomenon in evaluation. In Dominance Relations, D. Omark, F. Strayer., and D. Freedman (Eds.). New York: Garland Press, 1980, pp. 21-67.

Omark, D., Omark, M., Edelman, M. Formation of dominance hierarchies in young children. In $P s y-$ chological Anthropology, T. Williams (Ed.). The Hague: Mouton, 1975, pp. 289-315.

Parten, M. Social play among preschool children. Journal of Abnormal and Social Psychology 26: 243-269 (1932).

Savin-Williams, R. An ethological study of dominance formation and maintenance in a group of human adolescents. Child Development: 47, 972-979 (1976).

Savin-Williams, R. Dominance hierarchies in groups of early adolescents. Child Development 50: 923935 (1979).

Savin-Williams, R. Social interactions of adolescent females in natural groups. In Friendship and Social Relations in Children, H. Foot, A. Chapman, and J. Smith (Eds.). New York: John Wiley \& Sons, 1980, pp. 343-364.

Strayer, F. Social ecology of the preschool peer group. In Minnesota Symposia on Child Psychology Vol. 13, W.A. Collins (Ed.). Hillsdale, New Jersey: Erlbaum, 1980, pp. 165-196.

Strayer, F. The organization and coordination of asymmetrical relations among young children: A biological vicw of social power. New Directions for Methodology of Social and Behavior Science 7: 3349 (1981).

Strayer, F., Strayer, J. An ethological analysis of social agonism and dominance relations among preschoolers. Child Development 47: 980-989 (1976).

Vaughn, B., Waters, E. Attention structure, sociometric status, and dominance: Interrelations, behavioral correlates, and relationship to social compe- 
tence. Developmental Psychology 17: 275-288 (1981).

Waldrop, M., Halverson, C. Intensive and extensive peer behavior: Longitudinal and cross-sectional analyses. Child Development 46: 19-26 (1975).
Weisfeld, C., Weisfeld, G., Callaghan, J. Female inhibition in mixed-sex competition among young adolescents. Ethology and Sociobiology 3: 29-42 (1982). 